\title{
The effects of maintenance diet on adaptation to food or water deprivation schedules in the rat'
}

GLENN I. HATTON, MICHIGAN STATE UNIVERSITY LAWRENCE I. O'KELLY, UNIVERSITY OF ILLINOIS

\begin{abstract}
Rats maintained on three different diets were adapted to: (a) 23.5-hr. water deprivation, (b) ad lib conditions, and (c) 23.5-hr. food deprivation, in that order. After 16 days on food deprivation a diet switch was made. Results showed a diet slightly higher in fat content to be superior in terms of limiting initial weight loss and returning Ss to predeprived weights. The diet switch produced immediate and profound effects on weight and amount of food eaten, indicating a strong taste preference factor.
\end{abstract}

\section{Problem}

As recently pointed out by Davenport \& Goulet (1964), normal growth-age relationships and constant motivational levels can be obtained by the rather effortful and time-consuming adjusted percentage technique. However, that method is limited in applicability to studies (a) employing food deprivation and (b) in which the time budget allows daily weighing of all Ss. The present experiment attempts to show that the investigator who finds the adjusted percentage method unreasonable or undesirable need not consider "motivational artifact" to be the inescapable alternative.

\section{Method}

Phase 1 of the study was designed to investigate the effects of different diets on body weight (BW) and water intake of rats maintained on a 23.5-hr. water deprivation schedule. The Ss were 11 male albino rats, ca. 150 days old at the start of the experiment. The diets used were two regular rat foods, designated LB and LC, and a mouse breeder food, denoted BB. The differences in these foods were in their protein, fat and fiber content. The protein contents were: LC-23\%; LB-24\%; BB-20\%. The fat contents were: LC-4.5\%; LB-4\%; BB-10\%. The fiber contents were: LC-6\%; $\mathrm{LB}-4.5 \% ; \mathrm{BB}-2 \%$. In addition to these differences, the BB diet is less firmly bound and, thus, more easily broken up than are the other two.

The Ss were housed in group cages with food constantly present during Phase 1. There were three Ss in the LC group and four Ss in each of the other two groups. The $0.5-\mathrm{hr}$. daily period of access to water was given in individual drinking boxes equipped with $100 \mathrm{ml}$ gas measuring tubes which allowed precise measurement of water intake. The Ss were weighed once daily, just prior to drinking. After 33 days on this regimen, ad lib food and water conditions were instituted and maintained for 17 days.

Phases 2 and 3 of the experiment were designed to investigate the effects of (a) the different diets and

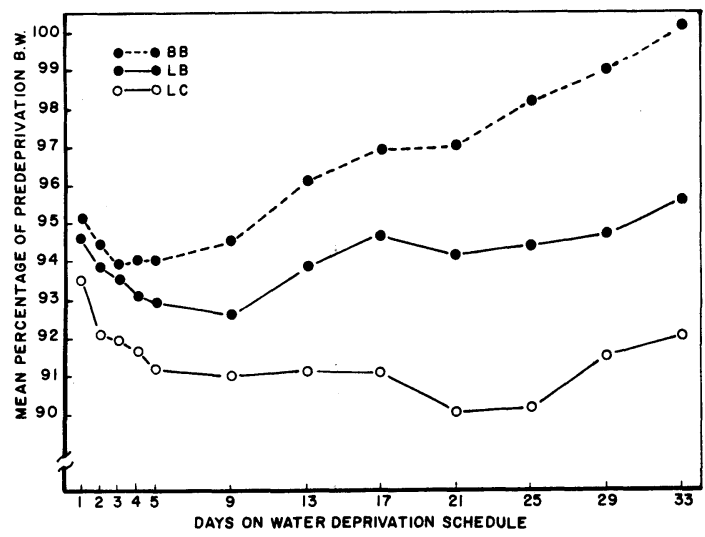

Fig. 1. Mean percentage of predeprivation body weight as a function of days on a $23.5-\mathrm{hr}$. water deprivation schedule.

(b) a switch in diet on BW and food intake while Ss were on a 23.5-hr. food deprivation schedule. Following the 17 days of ad lib conditions, Ss of Phase 1 were put on a $0.5-\mathrm{hr}$. per day feeding schedule. Water was constantly present in their living cages, but not available during the feeding period. The Ss were fed their respective diets in individual hardware cloth cages, into which about 40-50 gm of food had been placed. BW was recorded immediately before and immediately after feeding. The difference between the two weights was taken as the index of food intake.

Seventeen days after the start of Phase 2, the BB diet was given to the LC and LB groups, and the LC diet was given to the BB group. This switch and deprivation conditions were maintained for nine days, and constituted Phase 3 of the experiment.

\section{Results}

A wet-and-dry-weight analysis of the three foods revealed that the LC diet contained $7 \%$ water, while water content of the $\mathrm{LB}$ and $\mathrm{BB}$ diets was $8 \%$.

The results of the weight data for Phase 1 are depicted in Fig. 1. By the 6th day of water deprivation, the means of the groups are significantly different at $\mathrm{p}<.05(\mathrm{~F}=5.55, \mathrm{df}=2 / 8)$. By day 25, the differences are reliable at $p<.005 \quad(F=11.81, d f=2 / 8)$. It is important to note also that while the water intake of the LB and LC groups were essentially equal throughout the course of Phase 1 (means of $4.50 \% \mathrm{BW}$ and $4.59 \% \mathrm{BW}$, respectively), the intake for the BB group was considerably lower $(3.84 \% \mathrm{BW})$. These means are reliably different at $\mathrm{p}<.025(\mathrm{~F}=6.35, \mathrm{df}=2 / 8)$. After the 6th day of ad lib conditions following Phase 1, 


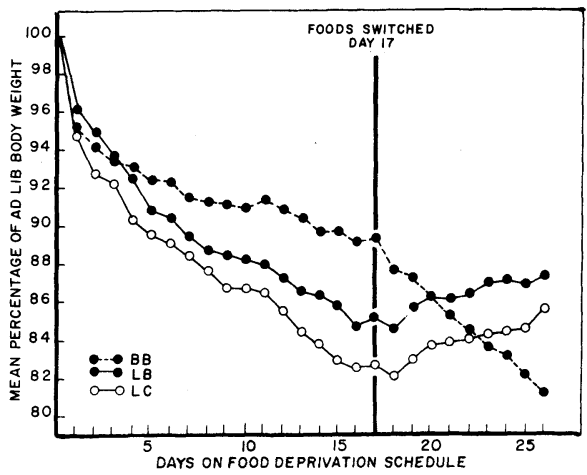

Fig. 2. Mean percentage of ad lib body weight as a function of days on a $23,5-h r$, food deprivation schedule.

there were no reliable BW differences among the groups.

The BW data for Phase 2 are plotted in Fig. 2. The means for the LB and LC groups do not differ significantly. However, starting with day 7 and continuing through day 17 , the $\mathrm{BW}$ measures for the $\mathrm{BB}$ group do not overlap with those for either of the other two groups. An analysis of variance on the data of day 17 yielded: $F=33.69$, df $2 / 8(p<.001)$.

The food intake means plotted in Fig. 3 show that, prior to the diet switch, the BB group was consuming somewhat larger amounts of food than the other groups. Occasionally these differences reached statistical significance. The effects of the food switch of Phase 3 are shown in the right hand portions of Fig. 2 and 3. On day 26, the distributions of BWs for the BB group vs. either the LB or LC groups do not overlap. This same non-overlap result occurs on day 17 for the food intake measure, and lasts throughout the duration of the switch.

\section{Diseussion}

From the data of this experiment, it is clear that the proper diet selection can greatly influence the rate at which rats on a 23.5-hr. water deprivation schedule regain their predeprivation weights. Of perhaps greater importance to most experimenters is the limiting of initial weight loss to $6 \% \mathrm{BW}$ and the period of that loss to three days in the $\mathrm{BB}$ group of the present study. This short-term, relatively small weight loss has been replicated on at least two occasions (Hatton \& O'Kelly, 1964, unpublished; Kutscher, 1964). When the LC diet has been used in conjunction with 23.5-hr. water deprivation schedules (Beck, 1962), weight losses

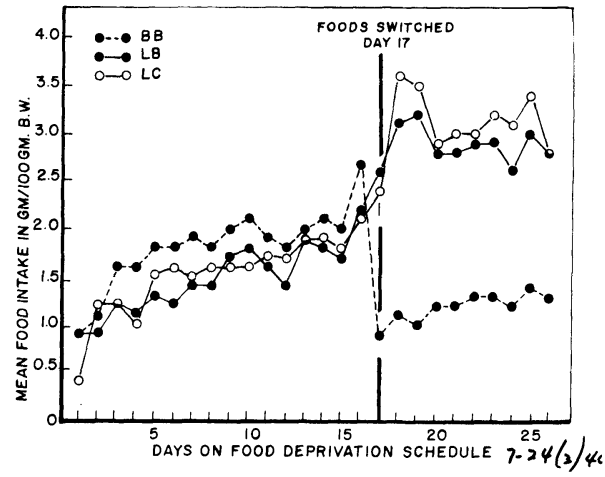

Fig. 3. Mean food intake in $\mathrm{gm} / 100 \mathrm{gm}$ of body weight as a function of days on a $23.5-\mathrm{hr}$. food deprivation schedule.

have been similar in extent and duration to those of the LC group reported here.

The finding that Ss which lost the least weight and regained to their predeprived level were doing so while drinking less water than the other Ss was quite unexpected. The considerably greater fat content of the $\mathrm{BB}$ diet accounts for this finding, since fats yield ca. $1 \mathrm{gm}$ of metabolic water per gm of dietary fat (Crampton \& Lloyd, 1959). This would mean that the BB Ss were getting roughly twice as much water of metabolism per gm of food eaten.

The results of the food deprivation Phase of this study show quite clearly that the BB diet is superior to the other diets in terms of limiting weight loss. The effects produced by the diet switch seem to be accountable entirely in terms of relative palatability and taste preference.

In summary, the choice of a maintenance diet seems to be an important factor to be considered when the motivational artifacts of Davenport \& Goulet (1964) are a possible source of error and the adjusted percentage method is infeasible.

\section{References}

Beck, R. C. The rat's adaptation to a 23.5-hour water-deprivation schedule. J. comp. physiol. Psychol:, 1962, 55, 646-648.

Crampton. E. W., \& Lloyd, L. E. Fundamentals of nutrition. San Francisco: W, H. Freeman \& Co., 1959.

Davenport, D. G., \& Goulet, L. R. Motivational artifact in standard food deprivation schedules, J. comp. physiol. Psychol., 1964, 57, 237-240.

Kutscher, C. L. Some physiological correlates of adaptation to a water deprivation schedule. In M. J. Wayner (Ed.), Thirst. Oxford: Pergamon Press, 1964. Pp. 257-269.

\section{Notes}

1. This research was supported in part by Public Health Service Fellowship MF 134-64 and Grant M-4853, both from the National Institute of Mental Health. 